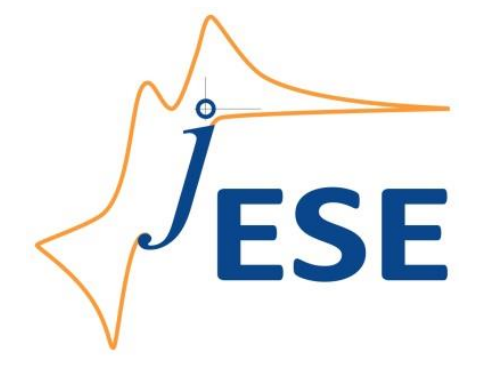

Open Access : : ISSN 1847-9286

www.jESE-online.org

Original scientific paper

\title{
Ellipsometric study of passive and anodic oxide films formed on $\mathrm{Ti}$ and $\mathrm{Nb}$ electrodes
}

\author{
Ljubomir Arsov $\bowtie$, Irena Mickova \\ Faculty of Technology and Metallurgy, University Ss. Cyril and Methodius, Rudjer Boskovic 16, \\ 1000 Skopje, Republic of Macedonia \\ ${ }^{\bowtie}$ Corresponding Author: arsov@tmf.ukim.edu.mk; Tel. +389 23088 43; Fax: + 38923065389
}

Received: October 20, 2015; Accepted: November 26, 2015

\begin{abstract}
Electrochemical formation of passive films and active/passive transition on $\mathrm{Ti}$ and $\mathrm{Nb}$ metal surfaces in various concentrations of $\mathrm{H}_{2} \mathrm{SO}_{4}$ and $\mathrm{KOH}$ solutions was investigated using potentiostatic and cyclic voltammetry methods. By simultaneous electrochemical and in-situ ellipsometric measurements the coefficients of film thickness growth of passive films in the potential region from $-1.5 \mathrm{~V}$ to $4 \mathrm{~V}$ were determined. Results indicate the strong influence of the concentration and electrolyte nature to the active/passive transitions and stability of passive films. The influence of cathodic pre-treatment on the passive films dissolution and appearance of the reactivation peaks during the reverse potential cycling were shown. By multiple cycle sequences in which the final anodic potential was gradually enlarged, the barrier properties of passive films on investigated electrodes were confirmed. The electrochemical and ellipsometric data showed that the passive films formed on $\mathrm{Nb}$ electrode are more resistant that passive films formed on $\mathrm{Ti}$ electrode, especially in higher concentrations of investigated aggressive solutions.
\end{abstract}

\section{Keywords}

Potentiostatic method, Cyclic voltammetry, Film thickness growth, Stability and reactivation of passive films

\section{Introduction}

Over the past 50 years there has been a growing interest for the use of titanium and niobium, as well as theirs alloys, in various branches of the chemical and mechanical industry as construction materials, specifically in transport and stocking of aggressive fluids. They have been also used in electro-synthesis, solar energy conversion bio-medical and air-space applications. Research on the electrochemical behavior of $\mathrm{Ti}$ and $\mathrm{Nb}$ have covered the wide range of topics as 
active-passive transition [1-2], formation of anodic oxide films [3-4], structure and chemical composition, breakdown processes [5-6], semi-conducting and optical properties [7-8] etc. Titanium and niobium belong to the group of valve metals because they develop spontaneously the stable passivating layers either when contacting air and/or water solutions. These layers in reality are natural oxide films, which are always present on $\mathrm{Ti}$ and $\mathrm{Nb}$ surfaces and explain their high corrosion resistance. In order to increase the corrosion resistance of $\mathrm{Ti}$ and $\mathrm{Nb}$, the natural oxide films can be controllably thickened by anodic oxidation in appropriate electrolytes or by thermal oxidation in atmospheric conditions $[9,10]$. The anodic oxide film formation on $\mathrm{Ti}$ and $\mathrm{Nb}$ electrodes have been studies in some acid and alkaline electrolytes, using ellipsometry and other electrochemical and optical techniques, but generally for potentials/voltages higher than the trans-passive region [11,12]. Although the studies of metal passivity exist for almost 200 years, in literature data can be found very rarely the use of elliposmetric methods for determining the film thickness only in passive region during the cyclic voltammetry CV measurements. A few information's can be found in ref. [13] about the formation of passive films on Ti electrode in 0.1 $\mathrm{M} \mathrm{H}_{2} \mathrm{SO}_{4}$ depending of sweep rate and in one of our recent papers concerning the thickness growth and dissolution of electrochemical passive film on $\mathrm{Nb}$ in $10 \mathrm{M} \mathrm{KOH} \mathrm{[14].}$

The purpose of present investigations is to study the active passive transition of $\mathrm{Ti}$ and $\mathrm{Nb}$ electrodes, simultaneously with in-situ ellipsometric measurements. In that way is expected to get valuable results about the film thickness growth for each applied potential during the potentiostatic and CV scans measurements in forward and reverse potential directions. The comparative studies of $\mathrm{Ti}$ and $\mathrm{Nb}$ in acidic and alkaline solutions are carried out.

\section{Experimental}

Electrodes. Massive cylindrical $\mathrm{Ti}$ and $\mathrm{Nb}$ rods (Alfa Aesar, Johnson Matthey Company), with purity $99.95 \%$ and $99.8 \%$ respectively and with $12.7 \mathrm{~mm}$ dia., were cut in disc species with length of $10 \mathrm{~mm}$ which were served as the working electrodes. On one basis of the disc a shout cooper wire was employed as the electrical contact. The discs were fitted into glass tubing of appropriate internal diameters by an epoxy resin (Struers), leaving the other basis with surface area of 1.27 $\mathrm{cm}^{2}$ to contact the solution. Before each experiment the electrode surfaces were mechanically polished using metallographic emery paper 600 and then electro-polished to the mirror brightness in the baths: (i) for Ti electrodes containing: $60 \mathrm{ml}$ perchloric acid $+540 \mathrm{ml}$ methyl alcohol $+350 \mathrm{ml}$ ethylene glycol mono butyl ether. The electro polishing conditions are given in ref. [15], (ii) for $\mathrm{Nb}$ electrodes containing: $170 \mathrm{ml}$ nitric acid $+50 \mathrm{ml}$. hydro fluoric acid $+510 \mathrm{ml}$ methyl alcohol $+5 \mathrm{~g}$ citric acid at voltage of $15.2 \mathrm{~V}$. After electro-polishing the electrodes were rinsed with re-distilled water, ultrasonically cleaned in ethanol and finally dried using argon gas under pressure.

The counter electrode was a Pt grid with large surface area. The reference electrode was a saturated calomel electrode (SCE) in acidic aqueous solutions and mercury oxide electrode in alkaline aqueous solution. The potentials in this work are presented against using reference electrode. To avoid contamination, the reference electrodes were connected to the working electrode through the bridges with a Luggin capillary filled with the test solutions. After each experiment the working electrodes were mechanically re-polished and prepared for the next measurements using the procedures of electro-polishing as described above.

Optical Electrolytic cell. A three compartment optical electrolytic cell with an inlet and outlet for bubbling inert gas was adopted for electrochemical and ellipsometric in-situ measurements. Experiments were done in a Pyrex vessel with two optical quartz widows fixed at an angle of $70^{\circ}$. 
The specimen surfaces were mounted vertically, with a rigid clamping system having adjustments for rotation, tilt and central positioning in the cell. Details of the design of this optical electrolytic cell are given elsewhere [16]. Prior to each experiment, when the electrode was immersed in the electrolyte solution, the electrolyte in the cell was de-aerated by flowing argon gas through a fritted bubbler for at least $30 \mathrm{~min}$. before the run. The gas flow was disconnected during the run.

Solutions. Aqueous solutions Merck p.a. with concentrations of $1 \mathrm{M} \mathrm{H}_{2} \mathrm{SO}_{4}, 3 \mathrm{M} \mathrm{H}_{2} \mathrm{SO}_{4}, 1 \mathrm{M} \mathrm{KOH}$ and $6 \mathrm{M} \mathrm{KOH}$ was prepared in re-distilled and de-ionized water. After each experiment the electrolyte in the cell was exchanged in order to avoid eventual build-up of soluble $\mathrm{Ti}$ or $\mathrm{Nb}$ species.

Apparatus. The electrochemical measurements were carried out potentiostatically and potentio-dynamically using HEKA model 488 potentiostat/galvanostat connected to a personal computer.

The ellipsometric measurements were performed with a Rudolph Research type 43603-200 thin-film ellipsometer at a wavelength of $546.1 \mathrm{~nm}$ and an incident angle of $70^{\circ}$

\section{Results and discussion}

Electrochemical passivity of $\mathrm{Ti}$ and $\mathrm{Nb}$ has been mainly studied using galvanostatic, potentiostatic, potentiodynamic and EIS techniques [17-20]. In this paper we used potentiostatic and potentiodynamic methods combined with ellipsometry. Ellipsometry, also known as reflection polarimetry, is a very precise method for determining the optical constants, thickness and nature of reflecting surface, especially the metal surfaces with and without existence the thin films on them. This method derives its name from the measurements of the elliptically polarized light results from optical reflection from the investigate surface [21]. Hence, ellipsometry finds applicability in a wide variety of fields such as physical, chemical and micro-electronic engineering, corrosion, electrochemical and chemical formation of passive layers on metals, oxides, polymer films semiconductors, biology, medicine etc. The main strength of this technique lies in its capability to allow in-situ measurements and simultaneous determination of many optical parameters necessary to quantify the investigated system. The new generation of ellipsometers allows determination the film thicknesses of from $0.1 \mathrm{~nm}$ to $30 \mu \mathrm{m}$.

In ellipsometric measurements the experimentally measured parameters $\Delta$ and $\psi$ are related to the physical properties of the system by the use of Fresnel's equation

$$
\rho=r \mathrm{p} / r_{\mathrm{S}}=\operatorname{tg} \psi \cdot \exp (i \cdot \Delta)
$$

In Eq. 1, tg $\psi$ represents relative amplitude attenuation, $\Delta$ is relative phase change, $i$ is imaginary number, $r p$ and $r$ s represent the Fresnel reflection coefficients for electromagnetic wave polarized parallel and perpendicular to the plane of incidence, respectively. For a three component system, the ellipsometric parameters $\Delta$ and $\psi$ are complex function of the following parameters.

$$
\operatorname{tg} \psi \cdot \exp (i \cdot \Delta)=\left(\hat{\mathrm{n}}_{\mathrm{m}}, \hat{\mathrm{n}}_{\mathrm{f}}, \hat{\mathrm{n}}_{\mathrm{s}}, d, \lambda, \phi\right)
$$

In Eq. 2, $\hat{n}_{m}$ is complex refractive index of medium, $\hat{n}_{f}$ - complex index of film, $\hat{n}_{s}$ - complex index of metal substrate, $d$ - film thickness, $\lambda$-wavelength of incidence electromagnetic wave and $\phi$ - angle of incidence. To minimize the unknown parameters in Fresnel's equation the refractive index of medium (electrolytic solutions) could be determine with Abbe's refractometer, refractive index of metal substrate by some separate methods, for example elipsometrical measurements in 
vacuum of evaporated metal on microscope glasses. The other parameters as: wavelength $\lambda$, was given in dependence of used laser and angle of incidence $\phi$ was adjusted to the ellipsometer. By method of mathematical iteration, using computer program, the film thickness and complex index of refraction are determined. In our case the experimentally measured parameters $\Delta$ and $\psi$ are fitted with theoretically calculated curves for $\Delta$ and $\psi$ for increasing direction of film thickness for in advance given step of film growth.

\section{Passive film on titanium electrode}

After electropolishing, the $\mathrm{Ti}$ electrodes were immersed in $\mathrm{H}_{2} \mathrm{SO}_{4}$ solutions with various concentrations and open circuit potential, OCP, was recorded during the establishment of steady state potential, i.e. when the variations of potentials with time are negligible. The potentiostatic measurements were initiated from steady state potential with successive increasing the potential on the same electrode up to begin the evolution of oxygen in trans-passive region. Then, on the same electrode the potential was also successively changed in the reverse, cathodic direction up to value of starting potential. The variation of currents with time during establishment of steady state conditions were recorded for each successive change of potential. The steady state currents were then taken in construction of potentiostatic curves. Fig. 1 (a) illustrates the profile of one typical potentiostaic curve in the potential region from 0.75 to $3.5 \mathrm{~V}$. In the first forward scan an active dissolution region exists and the anodic current increases exponentially with potential up to point $a$, where the anodic current peak is formed. In this region two processes take place: metal dissolution and in the same time growth of anodic oxide film. However, the metal dissolution is prevalent process. In the second region the anodic current decreases toward a low value corresponding to the beginning of the passivation. The passive film formation and its growth with imposed potential are followed with long current plateau whose values are near to zero. The third region corresponds to trans-passive region, point $c$, where anodic current begin again to increase. In the first forward scan simultaneously with potentiostatic current-voltage, the ellipsometric measurements were also performed during imposed potentials. From ellipsometrically measured parameters $\Delta$ and $\psi$ the film thicknesses were calculated, presented in fig. 1 (b). For calculation the film thicknesses the input data in equation (1) and (2) were: for $3 \mathrm{M} \mathrm{H}_{2} \mathrm{SO}_{4} \hat{n}_{m}=1.364$, for virgin Ti substrate $\hat{n}_{\mathrm{s}}=2.94(1-1.217 i)$, for wavelength of incident light $\lambda=546.1 \mathrm{~nm}$ and for angle of incidence $\phi=70^{\circ}$, whereas the unknown values of $\hat{n}_{f}$ and $d$ were calculated by fitting the theoretical data to the experimentally measure ones. The fitting procedure was performed by a special prepared computer program in which $\hat{n}_{f}$ was searched for prior given values of the thicknesses in increments' of $1 \mathrm{~nm}$, in an increasing direction. The number of theoretical $\Delta-\Psi$ points on the theoretical fitted curves depend of the thickness increments' given from our side. Taking into account that our ellipsomteric measurements were performed in one relatively short potential region where the final film thickness at the end of the passive region is relatively low, the large dispersion of experimental points from the theoretically fitted curves is expected. During the computation only one theoretical function $T=f(\Delta T-\psi T)$ was searched from the family of theoretical functions which had minimal distance to the experimental measured points $\Delta E-\Psi E$. In determination the thicknesses of passive films the theoretical values of $(\Delta T-\Psi T)$ were taken in consideration whereas experimental dispersion of measure points $\left(\triangle E-\Psi_{E}\right)$ were neglec-

ted. Details of computer program and fitting procedure are given in ref. [22]. 
a

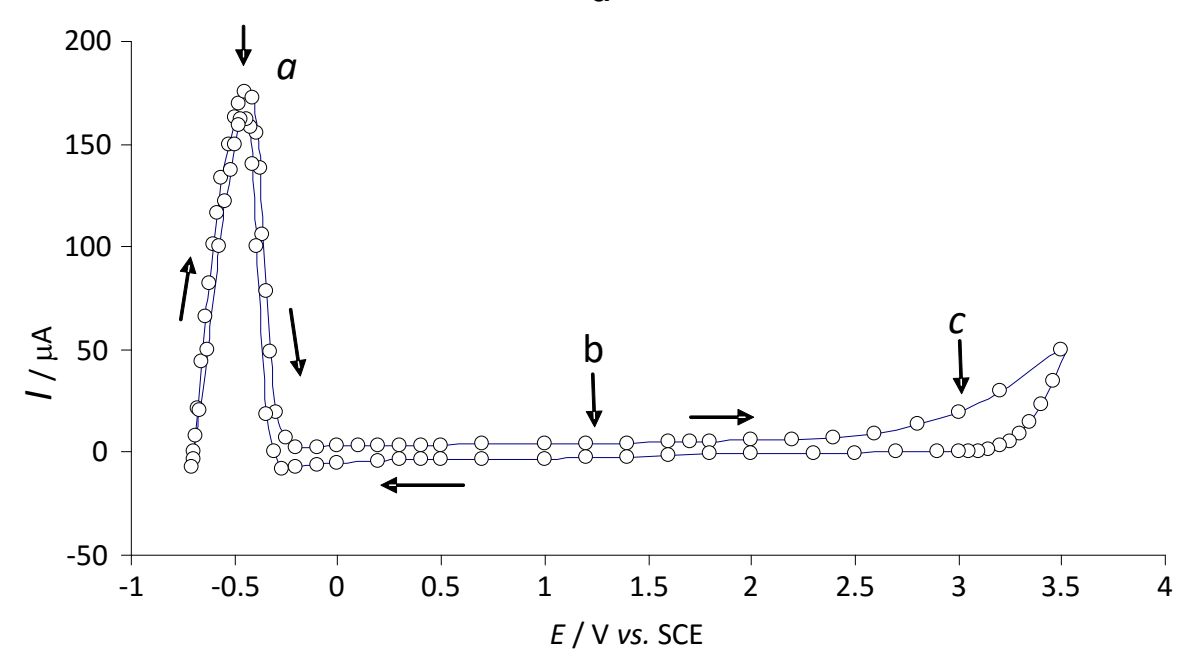

b

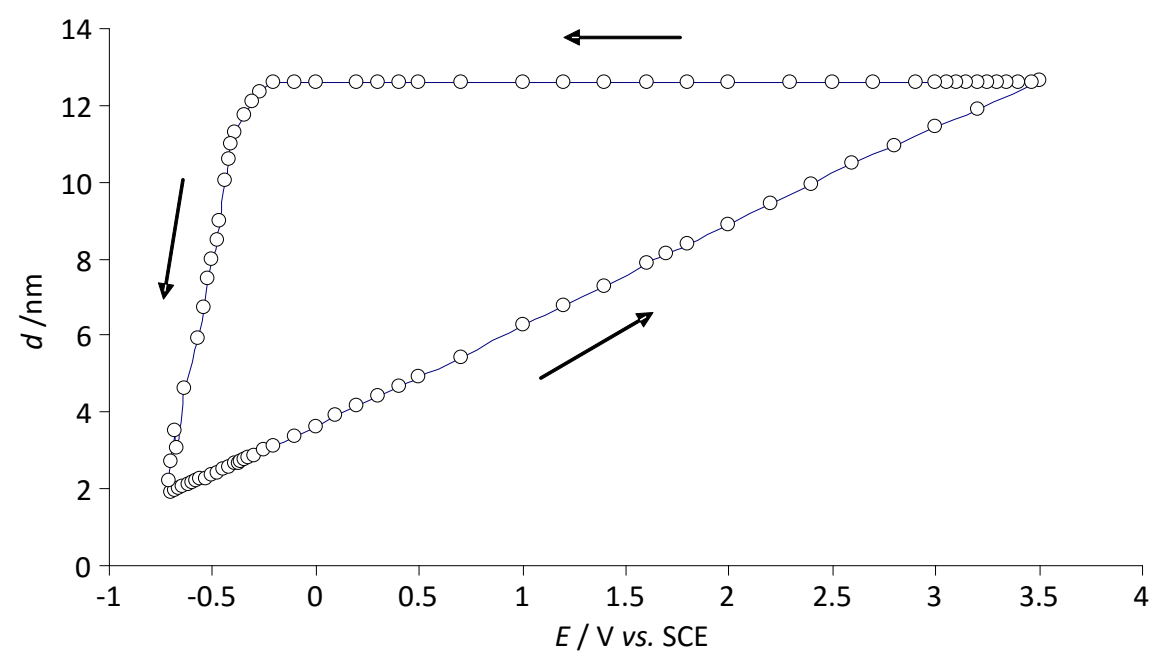

Fig. 1. (a) Potentiostatic I - E curve obtained on electropolished Ti surface in $3 \mathrm{M} \mathrm{H}_{2} \mathrm{SO}_{4}$,

(b) Simultaneous determination the thickness of passive film by ellipsometry

As it can see from fig. 1 (b) in the forward cycle the film thickness increases almost linearly and there is no noticeable dispersion of points which present growth of film thickness. From the slope of forward curve the coefficient of film thickness growth is determined, i.e. $\alpha=2.51 \mathrm{~nm} / \mathrm{V}$. In the reverse potential scan, with decrease of imposed potential in cathodic direction up to potential of $-0.25 \mathrm{~V}$, the long current plateau with current values also near to zero are observed. In this potential region ellipsometric measurements show that the thickness of the already formed passive film has constant value and there is no indication for its dissolution and thinning. At potential of $-0.25 \mathrm{~V}$ begins reactivation process with sharp increase of anodic currents indicating electrochemical dissolution of the formed passive film. The reactivation peak already covers the activation. In the potential region between $-0.25 \mathrm{~V}$ and $-0.75 \mathrm{~V}$, corresponding to the reactivation processes, the passive film was subject of continuously thinning and at the final potential of -0.75 $V$ the film thickness is minimized and already has the same value as at the starting potential of the first forward scan. This indicates that the formed passive film is completely dissolved. 


\section{Passive film on niobium electrode}

In the similar way as in case of $\mathrm{Ti}$, the $\mathrm{Nb}$ electrode was electropolished and then immersed in $\mathrm{H}_{2} \mathrm{SO}_{4}$ solutions with various concentrations and the OCP was recorded during the establishment of steady state potential. The potentiodynamic measurements were initiated at potential of -0.75 $\checkmark$ where a considerable cathodic current is observed and ended at $1 \mathrm{~V}$ (SCE), fig. 2(a)

a

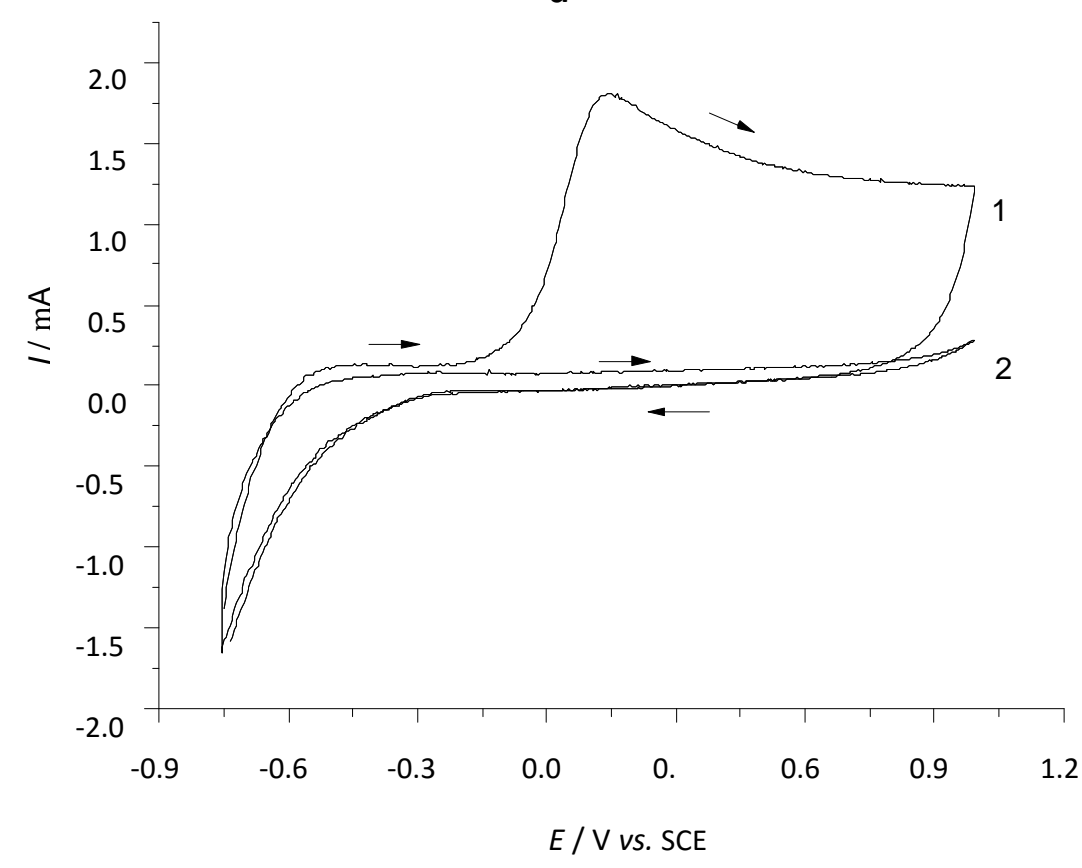

$\mathrm{b}$

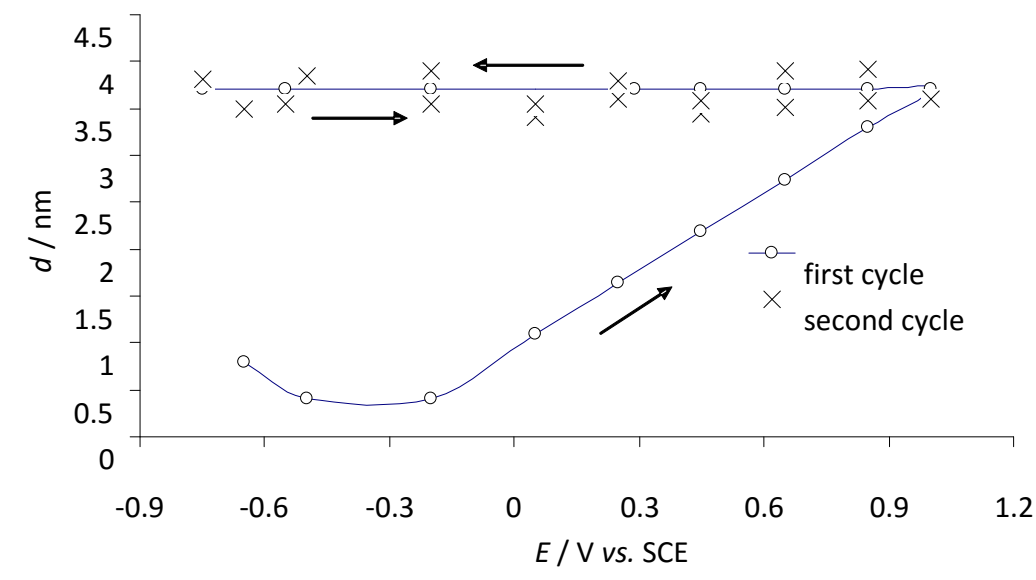

Fig. 2. (a) Voltammograms of $\mathrm{Nb}$ recorded in $10 \mathrm{M} \mathrm{H}_{2} \mathrm{SO}_{4}, 1$ - first cycle, 2 - second cycle;

(b) Simultaneous determination the thickness of passive film by ellipsometry

In the first forward scan the cathodic current approaches zero value and when it get anodic values the process of metal dissolution and in the same time formation of anodic oxide films occur, as in case of titanium electrode. The active-passive transition exists in all investigated concentrations, but with increasing the concentration of $\mathrm{H}_{2} \mathrm{SO}_{4}$ this process is more pronounced. During the reverse scan the reactivation processes or reduction of the already formed passive films were no recorded, even in high concentration of $\mathrm{H}_{2} \mathrm{SO}_{4}$ up to $10 \mathrm{M}$. This was the main reason why our measurements started at more cathodic potential where the noticeable catholic current appears in the beginning of the first forward scan and in each other next subsequent scans. It was expected that the natural or later formed passive films will be reduced at second scan during the 
cathodic polarization of electrode. But the passive film formed in first forward scan cannot be cathodically reduced in the reverse scan. In the second cycle a constant current close to zero, for both, forward and reverse scans were recorded. The voltammograms in the next subsequent scans were almost identical to the second one. It is evident that after the first cycle, the $\mathrm{Nb}$ electrode remained passive over the whole investigated potential region and the formed passive film blocked all possible redox reaction at the $\mathrm{Nb} /$ passive film/electrolyte interface. Compeering the $\mathrm{CV}$ curves between $\mathrm{Nb}$ and $\mathrm{Ti}$ electrode it can conclude that in $\mathrm{H}_{2} \mathrm{SO}_{4}$ solution the $\mathrm{Nb}$ is corrosion more resistant than $\mathrm{Ti}$ electrode. During the $\mathrm{CV}$ scans simultaneous ellipsometric measurements were also performed, as in casa of titanium electrode. From ellipsometric parameters $\Delta$ and $\Psi$ the film thicknesses were calculated fig 2 (b). In the beginning of the measurements, when cathodic current pass through the electrochemical cell, small decrease of the film thickness is observed, probably due to the partly dissolution of natural oxide film. With apparition of anodic current begin growth of anodic oxide film which is linear function up to the final anodic potential of 1 volt. From the slope of this linear curve the coefficient of film thickness grow of $\alpha=2.58 \mathrm{~nm} / \mathrm{V}$ was determined. In the first reverse scan the thicknesses of the film have constant values up to the starting potential of $-0.75 \mathrm{~V}$. In the second and subsequent scans the thickness of the film has almost the same constant values, as in the end of first forward and reverse scan. The dispersion of the measured points in the second scans could be observed, probably for small dissolutions of the passive film and its reparation during the potential scan, or by existing of some side reactions.

a

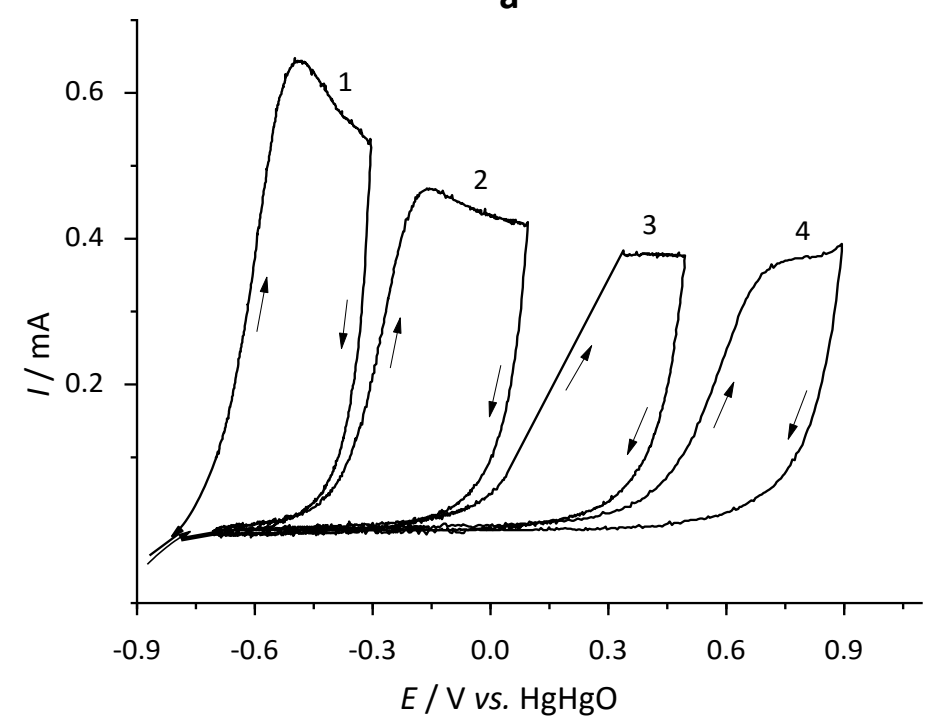

b

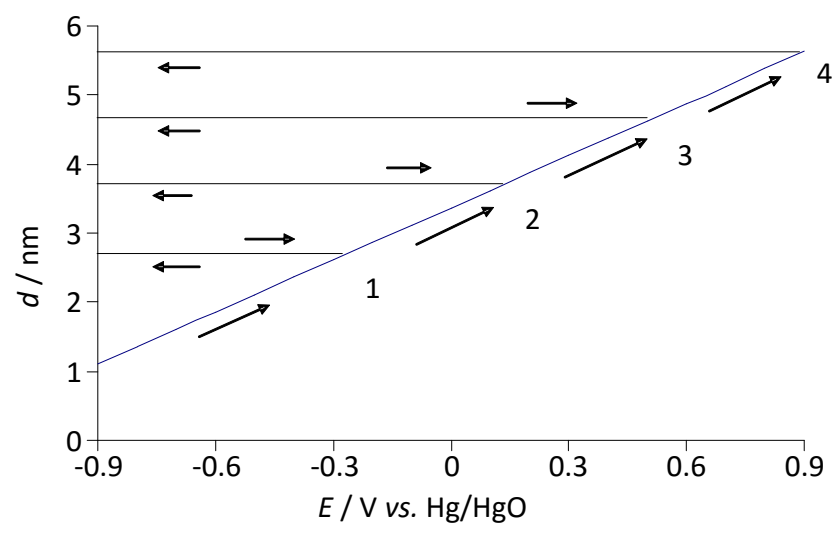

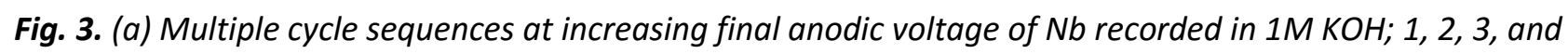
4 represent number of cycle, (b) Simulated film thickness growth in each subsequent cycle 
Fig. 3 (a) shows sequences of $\mathrm{CV}$ measurements where the final anodic potential on $\mathrm{Nb}$ in $1 \mathrm{M} \mathrm{KOH}$ is gradually enlarged in each next cycle. All subsequent presented voltammograms started from the same cathodic potential of $-0.9 \mathrm{~V}$ and also finished to the same catholic potential of $-0.9 \mathrm{~V}$. The difference in measurements is only to the increasing of final anodic potential. The progress of film thickness growth with anodic potential may take place only if the actual potential exceeds the maximum value attained in the previous cycle. The shapes of the sequences recorded in fig. 3 (a) represent just the copy segments of the corresponding voltammogram recorded from the starting potential at $-0.9 \mathrm{~V}$ to final potential at $0.9 \mathrm{~V}$ at once, without sequences. The simulated film thickness growth that should be obtained by ellipsometric measurements are presented in fig.3 (b).
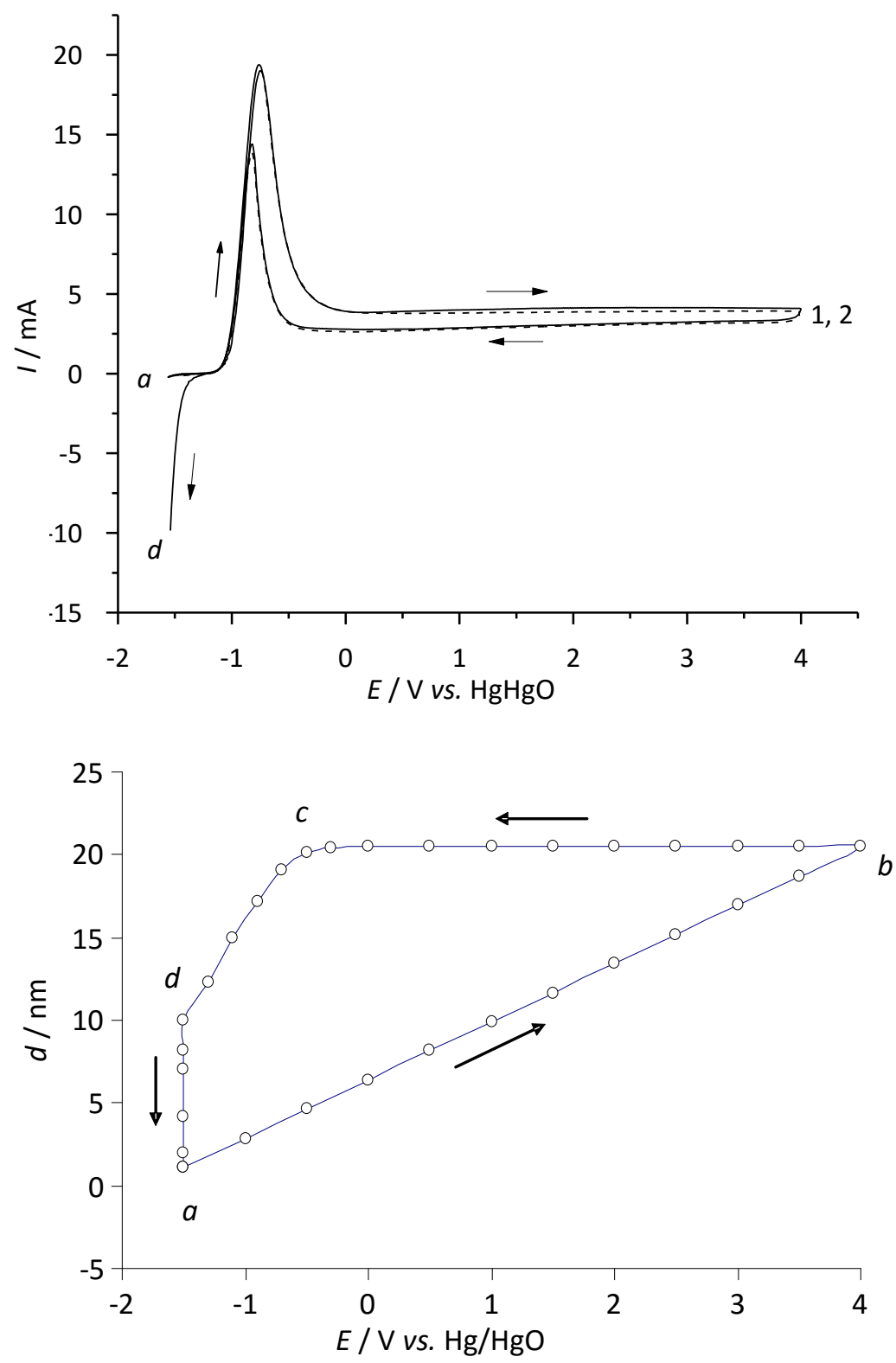

Fig. 4. (a) Voltammograms of $\mathrm{Nb}$ recorded in $6 \mathrm{M} \mathrm{KOH}$, a-initial current at potential of $-1.5 \mathrm{~V}$, $d$-final current at potential of -1.5 V, 1 -first cycle, 2 - second cycle;

(b) Simultaneous determination the thickness of passive film by ellipsometry, a-initial potential, $b$ - final anodic potential, $c$ - beginning of reactivation process,

$d$-final potential at -1.5 $\mathrm{V}$ after the first cycle, $d$-a -cathodic dissolution at -1.5 V during $15 \mathrm{~min}$ of the rest film thickness after its partly dissolution in the reverse scan. 
For each sequence, film thickness growth in the first forward scan and has constant value in the reverse scans. For each next sequence, in the first forward scan the film thickness has constant value up to the end of previous cycle and then continues to grow up to the final anodic potential. It is evident that by gradually increasing the final anodic potential the passive film grows by additional building of the new film on the already existing. The experiments in fig. 3 , confirm the barrier properties of anodic oxide film build on the Nb surface.

The voltammograms recorded on $\mathrm{Nb}$ at the higher concentration of $6 \mathrm{M} \mathrm{KOH}$ are shown in Fig. 4 (a). The starting cathodic potential was at $-1.5 \mathrm{~V}$ and final anodic potential at $4 \mathrm{~V}$. In the first forward scan at the initial potential of $-1.5 \mathrm{~V}$, point $a$, a small cathodic current occurs and then in the anodic direction active/passive transition is recorded. In the reverse scan, at potential of about $-0.5 \mathrm{~V}$, begin reactivation process which partly covers the activation region. This suggested that with appearance of reactivation peak only part of the formed passive film is dissolved. At the end of the first reverse cycle, at cathodic potential of $-1.5 \mathrm{~V}$, point $d$, the noticeable cathodic current flows through the electrochemical cell. If we keep for example $15 \mathrm{~min}$. the electrode at this potential and then initiate the second cycle, the voltammogram of the second cycle will be completely the same as in the first cycle. This indicates that after the first cycle, with keeping of some period of time the $\mathrm{Nb}$ electrode at $-1.5 \mathrm{~V}$, the previously formed passive film in the first cycle will be completely dissolved. The simultaneous ellipsometric measurements of the film thickness growth, presented in fig. 4 (b), showed continuous increasing of film thickness in the first forward scan and constant thickness values in the first reverse scan up to $-0.5 \mathrm{~V}$ where begin reactivation process. In the region of reactivation peak the film thickness partly decrease and did not reaches the initial value at $-1.5 \mathrm{~V}$, as before starting the CV measurements. During the keeping the electrode at potential of $-1.5 \mathrm{~V}$, the film dissolution continue and finally it get the same value as in the beginning of the first forward scan.

\section{Conclusions}

From potentiostatic and potentiodynamic measurments of $\mathrm{Ti}$ and $\mathrm{Nb}$ electrode in $\mathrm{H}_{2} \mathrm{SO}_{4}$ and $\mathrm{KOH}$ solutions, simultaneous with ellipsometric in-situ measurements, the following conclusions can be drawn: (i) Comparative studies of mechanically polished and electropolished metal surfaces have shown that the dispersion of experimental points from the theoretically fitted curves is smaller for electropolished metal surfaces. It should be noted that during the fine mechanical polishing with diamond spray, smooth surfaces with mirror brightness were obtained. However, mechanical polishing leaves numerous micro-surface scratches and defects with random distributions which cause areas of differing electrical potentials due to surface stress. This is the main reason why in this work we used electropolished metal surfaces instead of fine mechanical polished. (ii) The potentiostatic and potentiodynamic curves of $\mathrm{Ti}$ and $\mathrm{Nb}$ recorded in all investigation concentrations of $\mathrm{H}_{2} \mathrm{SO}_{4}$ and $\mathrm{KOH}$ solutions showed active passive transition with formation of passive films which are stable in lower concentration of investigated solution. (iii) For all investigated concentration of $\mathrm{H}_{2} \mathrm{SO}_{4}$ and $\mathrm{KOH}$ solutions, the passive film thickness growth on $\mathrm{Ti}$ and $\mathrm{Nb}$ electrodes are linear function with applied potential, up to final anodic potential in the forward scan. (iv) For Ti electrode in $3 \mathrm{M} \mathrm{H}_{2} \mathrm{SO}_{4}$, the passive films formed in the forward potentials were completely dissolved in the reverse potentials, where reactivation process was recorded. (v) For $\mathrm{Nb}$, even in $10 \mathrm{M} \mathrm{H}_{2} \mathrm{SO}_{4}$, the high stability of the passive films was recorded. In the reverse potential scan, no reactivation peak and dissolution of passive films was observed. (vi) In $6 \mathrm{M} \mathrm{KOH}$ the passive film on $\mathrm{Nb}$ electrode was partially dissolved with apparition of the reactivation peak 
whose current intensity is about half intensity of the activation peak. With keeping the electrode at potential of $-1.5 \mathrm{~V}$ the rest of the film was completely dissolved. (vii) Finally it can conclude that $\mathrm{Nb}$ electrode is more resistance in $\mathrm{H}_{2} \mathrm{SO}_{4}$ and $\mathrm{KOH}$ solutions than the Ti electrode.

\section{References}

[1] I. Mickova, A. Prusi, T. Grchev, Lj. Arsov, Portugaliae Electrochimica Acta 24 (2006) 377-385

[2] M. A. M. Ibrahim, D. Pongkao, Journal of Solid State Electrochemistry 6 (2002) 341-350

[3] A. Efremova, Lj. Arsov, Electrochimica Acta 37 (1992) 2099-2100

[4] R. Torresi, F. Nart, Electrochimica Acta 33 (1988) 1015-1018

[5] Lj. Arsov, C. Korman, W. Plieth Journal of Raman Spectroscopy 22 (1991) 573-575

[6] J. W. Schultze, M. M. Lohrengel, Electrochimica Acta 45 (2002) 2499-2513

[7] K. Heusler, M. Schultze, Electrochimica Acta 20 (1975) 237-244

[8] A. Prusi, Lj. Arsov, Corrosion Science 33 (1992) 153-164

[9] I. Mickova, International Review of Chemical Engineering 2 (2010) 692-701

[10] W. L. Lee, G. Olive, D. L. Pulfrey L. Young, Journal of the Electrochemical Society 117 (1970) 1172-1176

[11] A. Prusi, Lj. Arsov, B. Haran, B. Popov, Journal of the Electrochemical Society 149 (2002) B491-B498

[12] I. Arsova, Lj. Arsov, N. Hebestreit, A. Anders, W. Plieth, Journal of Solid State Electrochemistry 11 (2007) 209-214

[13] T. Ohtsuka, N. Nomura, Corrosion Science 39 (1997) 1253-1263

[14] I. Mickova, A. Prusi, T. Grchev, Lj. Arsov, Croatica Chimica Acta 79 (2006) 527-532

[15] Lj. Arsov, M. Froelicher, M. Froment, A. Hugot Le-Goff, Comptes Rendus de l'Académie des Sciences, Paris - Series C - électrochemie 279 (1974) 485-488

[16] Lj. Arsov, Electrochimica Acta 30 (1995) 1645-1657

[17] I. A. Amar, S. Darwish, M.W. Khalil, Materialwissenschaft und Werkstofftechnik, 12 (1981) 309-315

[18] S. L. Assis, I. Costa, Materials Researchs 10 (2007) 293-296

[19] M. T. Woldemedhina, D. Raabea, A. W. Hassel, Electrochimica Acta 82 (2012) 324-332

[20] M. K. Han, J. Y. Kim, M. J. Hwang, H. J. Song, Y. J. Park, Materials 8 (2015) 5986-6003

[21] Lj. Arsov, M. Ramasubramanian, B. Popov, Ellipsometry, Chapter in Book Methods in Materials Research 1 (2001) 8b.5.1-8b.5.10, John Wiley \& Sons Inc.

[22] A. Efremova, Lj. Arsov, Journal of Physics France 2 (1992) 1353-1361

(C) 2015 by the authors; licensee IAPC, Zagreb, Croatia. This article is an open-access article distributed under the terms and conditions of the Creative Commons Attribution license (http://creativecommons.org/licenses/by/4.0/) (cc) EY 